\title{
Managing a variable acute patient flow: categorising the strategies
}

\author{
Olle Olsson and Håkan Aronsson
}

\section{Linköping University Post Print}

\section{Tweet}

N.B.: When citing this work, cite the original article.

Original Publication:

Olle Olsson and Håkan Aronsson, Managing a variable acute patient flow: categorising the strategies, 2015, Supply chain management, (20), 2, 113-127.

http://dx.doi.org/10.1108/SCM-06-2014-0203

Copyright: Emerald Group Publishing Limited

http://www.emeraldinsight.com/

Postprint available at: Linköping University Electronic Press

http://urn.kb.se/resolve?urn=urn:nbn:se:liu:diva-111588 


\section{Managing a variable acute patient flow - categorising the strategies}

\section{Introduction}

The field of healthcare supply chain management is in its infancy, with a lack of academic research (Shah et al., 2008; de Vries and Huijsman, 2011), even though the potential of applying existing concepts, models and practices from logistics and supply chain management (SCM) has been emphasised (Aronsson et al., 2011; Towill and Christopher, 2005). There are also indications that the healthcare sector is behind the industry sector when it comes to implementing SCM practices (McKone-Sweet et al., 2005; de Vries and Huijsman, 2011). Research on how management philosophies, such as lean and agile manufacturing, are applied by healthcare providers and to what extent healthcare providers can benefit from these practices are therefore also needed (de Vries and Huijsman, 2011).

This study aims filling some of that gap by applying the concepts of lean and agile in a study in a health care setting, something that has been sparsely explored, even though there are examples (e.g. Aronsson et al., 2011; Rahimnia and Moghadasian, 2010). Although lean has been applied successfully in the private sector, limited research has evaluated whether the lean approach transfers successfully to the public sector and what impact the approach has on for example costs, productivity and quality of service (Radnor et al., 2006). With a lean approach the focus is on continually eliminating waste and thereby reducing the resources used to produce a given set of goods, with the ambition being to achieve a streamlined flow of production (Womack et al., 1990).

It could be argued that an overarching emphasis on cost and a supply-chain logic based on predictable demand patterns, high sales volumes, and low product variety may appear unsuitable to healthcare service delivery where availability of service is vital. Instead flexibility at different levels of healthcare provision is needed (e.g. Aronsson et al., 2011; Bohmer, 2005; de Vries and Huijsman, 2011; Lillrank et al., 2011; Rahimnia and Moghadasian, 2010; Towill and Christopher, 2005). An agile approach, designed to accommodate unpredictable demand including low volumes per individual 'product' and high levels of 'product' variety (Christopher and Towill, 2000) could provide the necessary flexibility in health care delivery. With a high speed of response (Christopher, 2000; Lin et al., 2006; Qrunfleh and Tarafdar, 2013) and the capability to change direction with ease (Kidd, 1995; Aitken et al., 2002), an agile strategy uses flexible capacities (Aronsson et al., 2011). Agility has not been extensively discussed in healthcare literature, although the combination of the two concepts has formed a discourse in literature on industrial supply chain settings (e.g. Naylor et al., 1999; Mason-Jones et al., 2000; Towill and Christopher, 2002; Aitken et al., 2002; Qrunfleh and Tarafdar, 2013). 
For both lean and agile it is important to reduce variation created by the organisations themselves. The difference lies in how externally created variation is handled. With an agile strategy, flexible capacities are used to respond to variations (Aronsson et al., 2011). In contrast, when it is not possible to eliminate variation, a lean strategy often includes protecting production from variations by using inventory, or in a healthcare context a queue. In healthcare, there is a high degree of variability (Ronen and Pliskin, 2006), specifically for acute patients where the patient inflow concerning time, health issues and response to treatment is highly variable (Bohmer, 2005) and externally created. Internally created variability comes from the way work within an organisation is done. Healthcare resources are often used inappropriately and not adapted to the variations that exist (Walley et al., 2006). Instead, variation is created internally by the behaviours in healthcare systems such as discontinuous scheduling, variable capacity to discharge and by splitting demand into subgroups (Allder et al., 2011). Thus, there is a need for better processes based on available knowledge on variation (McLaughlin, 1996). Since acute patient flows are inherently subject to high variability it is of interest to analyse how the strategies used to manage an acute patient flow can be related to lean, agile and leagile strategies. The purpose with this study is therefore:

To explore if actions used at a hospital to manage a variable acute patient flow can be categorised using the concepts of lean, agile and leagile.

To clarify, the purpose entails two objectives. The first is to identify actions used at a hospital and the second objective is to investigate if these actions can be categorised as being lean, agile and/or leagile. The appropriateness of actions used to manage a variable acute patient flow are thus not evaluated in this study.

The term acute patient is, in this paper, defined as a patient that arrives at the emergency department (ED), in need of medical assistance. An elective patient instead has a prior appointment and is planned to arrive for a specific medical treatment at a specific clinical department.

\section{Frame of reference}

Many authors discuss the use of lean and agile strategies as company-wide strategies (Kidd, 1995; Mason-Jones et al., 2000; Aitken et al., 2002). This paper instead explores and categorises individual actions as being lean or agile. To achieve this, lean and agile have been sub-divided into three categories respectively. These categories will be outlined after each process strategy has been discussed below.

\section{Agile}

The concept of agility originated in manufacturing and was first introduced with the publication in the USA of a report entitled 21st Century Manufacturing Enterprise Strategy (Goldman and Preiss, 1991). The concept of agility was developed as a response to the 
increasing rate of change and uncertainty in the business environment (Ismail and Sharifi, 2006). Many definitions of agility have been provided over the years, with considerable differences, but all have included the core of agility; being adaptable to change in the environment, whether it originates from the customer, competitors, legislation or other stakeholders. Further characteristics of agility are given below:

- Responsive - A high speed of response (Qrunfleh and Tarafdar, 2013), for example, to new market opportunities (Kidd, 1995) enabled by a close connection to enduser trends or shared information among supply chain partners (Christopher, 2000; Harrison et al., 1999; Aitken et al., 2002; Lin et al., 2006).

- Adaptable - The capability to change direction with ease. For example entering completely new markets or product areas (Kidd, 1995), by using individualised combinations of products and services in small lot sizes (Aitken et al., 2002). Creating flexibility through the use of specialist players and having a high degree of process integration between network members are other examples (Christopher, 2000; Harrison et al., 1999; Aitken et al., 2002; Lin et al., 2006).

- Robust - The ability to avoid and endure variations and disturbances, for example managing products that lose market appeal due to changes in customer preferences (Kidd, 1995). Mastery of uncertainty and variability has also been identified as a benefit associated with agility (Goldman et al., 1995).

Being responsive to a variable patient inflow could be represented by the capability to rapidly open up a new nursing ward to match the need generated by an increased patient inflow. Another example would be having sufficient amount of personnel and other resources available to manage the highest level of demand at a given period, in operations management terminology called a lead strategy. The advantage with this approach is that the next sub-process receives reliable deliveries in terms of timeliness.

To have a central pool of personnel, comprised of nurses with the competence to work at a few different departments could be a way to adapt to variations in the patient mix. Off course in the healthcare industry in general the exchangeability of tasks between individuals and positions are limited, due to the highly specialised areas of expertise. Process integration through explicit communication paths enhances the probability of gaining fast and accurate information concerning e.g. patient inflow. In order to be robust, tacit knowledge regarding the variation at hand must be developed. This includes mapping what types of variation are important to manage, what impact these have, and how to predict variations.

As a process strategy being agile would be to work with flexible capacity (Aronsson et al., 2011). As discussed previously, being agile incorporates being responsive, adaptable and robust. Flexible capacity is needed in order to achieve a high speed of response (Kidd, 1995; Christopher, 2000; Harrison et al., 1999; Aitken et al., 2002; Lin et al., 2006), a capability to change direction with ease (Kidd, 1995; Aitken et al., 2002), and to enable 
the management of uncertainty and variability (Kidd, 1995; Goldman et al., 1995). A capacity is created when a resource is used, in healthcare using personnel, equipment, beds or other resources. Flexibility is thus created by the ability to alter the amount of a resource or the ability to extend the use of a resource. Based on this division, the creation of a "new" resource is categorised as an ability to extend the use of a resource. The ability to alter the amount of a resource is further divided based on the alteration being done ahead of demand or as a response to demand. The three categories are thus:

1. Extending the use of a resource

2. Altering the amount of a resource, ahead of demand

3. Altering the amount of a resource, as a response to demand

It should be noted that all of these three categories requires some form of preparation or design to be able to use, but for this categorisation it is the actual use of the flexibility that is considered.

\section{Lean}

Lean production (lean) is developed from Toyota Production System, and the concept gained widespread attention through the bestseller The Machine that Changed the World (Womack et al., 1990). The basis of lean is the pursuit of waste: everything that does not add value to the product (Monden, 1983). Variation is considered to be waste and should therefore be eliminated (Bicheno, 2009). The objective in implementing lean is to enhance customer value by streamlining the flow of production while continually eliminating waste, thereby reducing the resources used to produce a given set of goods (Womack et al., 1990).

Within the healthcare sector lean is increasingly being applied, both in acute (Radnor et al., 2006; Joosten et al., 2009) and community settings (Grove et al., 2010a, b). Even though Lean approaches have been used in several hospitals around the globe, in most instances it has been used in order to create a platform from which more efficient production planning can be made. This could be called "lean basics" with the overall purpose of reducing waste and preparing the organisation for a change towards process orientation (Aronsson et al., 2011).

Concerning capacity management a lean strategy would be equivalent to having a fixed capacity and a high utilization of resources in the processes, e.g. personnel and equipment. Protection from external variation is therefore required. In the manufacturing sector variable supply and demand are often handled by having inventory of components and finished products. Services, including healthcare services, are not possible to store (Arlbjörn and Halldorsson, 2002). Instead queues are often used to protect against variation in healthcare, but must be of limited length dependent on the health issue at hand. The down-side with this approach is that the length of stay (LOS) for the patients will vary over time, depending on the number of patients that needs to be processed (see Figure 1). 


\section{Lean}

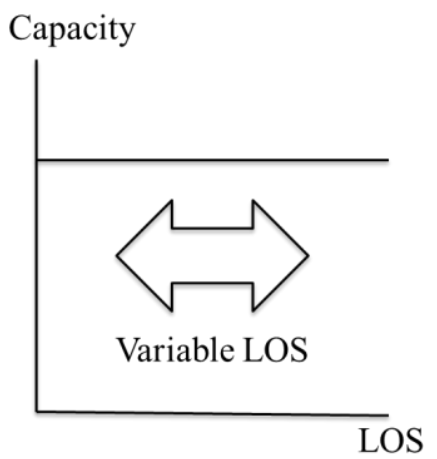

Agile

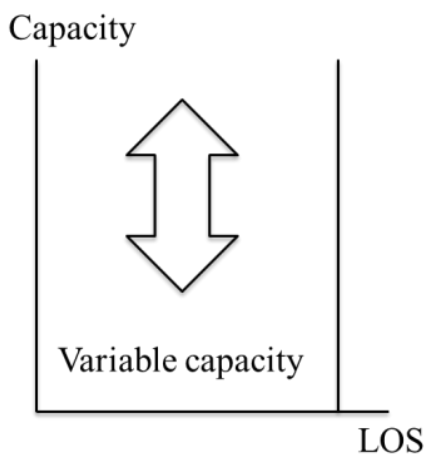

Figure 1 - Fixed or flexible, LOS or capacity (adapted from Aronsson et al., 2011, pp. 181)

An agile equivalent would be to work with flexible capacity and fixed LOS, calling for high availability of extra resources needed to perform the process on time. Reliability in terms of LOS is the advantage with this approach (see Figure 1).

A streamlined production process is a basis for a lean strategy (Womack et al., 1990). When handling acute patients, with variable inflow and responses to treatment, it is difficult to achieve a streamlined production process. Actions that create more standardised patient flow are therefore designated as the first of three lean categories. To eliminate waste and thereby reduce the resources needed to produce a given set of goods (Womack et al., 1990) is also important in a lean strategy. Since these two are closely related, and elimination of waste is more difficult to capture, actions that reduce the need for resources are considered a category. Within lean, variation is considered to be waste (Bicheno, 2009). An acute patient flow incorporates much variation in terms of inflow concerning time, health issues and response to treatment; to manage this external variation is therefore an important objective from a lean perspective and thus considered as a category. Hence, the categories are:

1. An action that increases patient flow standardisation

2. An action that reduces the need for a resource

3. An action that directly manage external variation

\section{Leagile}

Naylor et al. (1999) argue for the use of both a lean and agile strategy, instead of choosing between the two. The need for agility and leanness is dependent upon the positioning of the decoupling point with a lean strategy suitable upstream and the agile strategy advisable downstream from the decoupling point (leagile strategy), separating the part of the organisation oriented towards customer orders from the part based on planning. 
Therefore inventory is often held at the decoupling point as a buffer between fluctuating demand and smooth production output (Naylor et al., 1999; Mason-Jones et al., 2000).

By making a distinction between using "lean" and "agile" strategies based on a time/space matrix (see Figure 2) Towill and Christopher (2002) extended the discussion on leagility.

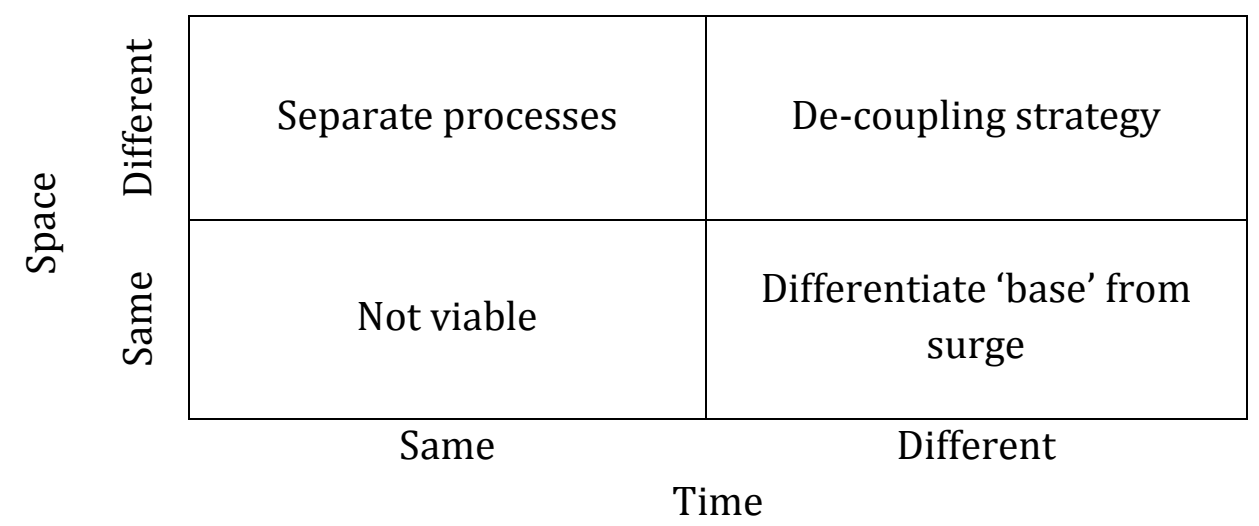

Figure 2 - The time/space matrix (Towill and Christopher, 2002, pp. 303)

The bottom right-hand corner suggests the opportunity to make and source a proportion of total expected demand ahead of forecasted need. This base level can be anticipated with high certainty allowing a lean strategy. Closer to the actual demand, additional capacity must be available to enable any "surges", for example through outsourcing or flexible partners (Towill and Christopher, 2002). A related hybrid strategy could be to use a level scheduling solution where surges in demand are met by adapting the use of capacity for base demand and thereby smoothing the capacity usage (Christopher and Towill, 2001). Healthcare services involving the patient cannot be performed ahead of demand. For healthcare services this strategy would therefore be represented by having a base-level of staff and beds, complemented with a preparedness to quickly increase staff and available beds if the need appear.

The top left-hand box represents using separate processes in parallel. An example is using a lean factory for predictable high-volume products and an agile factory for low-volume, less predictable products (Towill and Christopher, 2002). The combination of lean and agile approaches can be determined using the Pareto law (see Figure 3). Typically an analysis will show that the $80 / 20$ rule holds, meaning that 80 per cent of total volume will be generated from just 20 per cent of the total product line and vice versa. The top 20 per cent of products have bigger volumes and are likely to be more predictable, wherefore a lean approach could be appropriate. The slow moving 80 per cent will probably be less predictable and therefore require an agile approach (Christopher and Towill, 2001). 


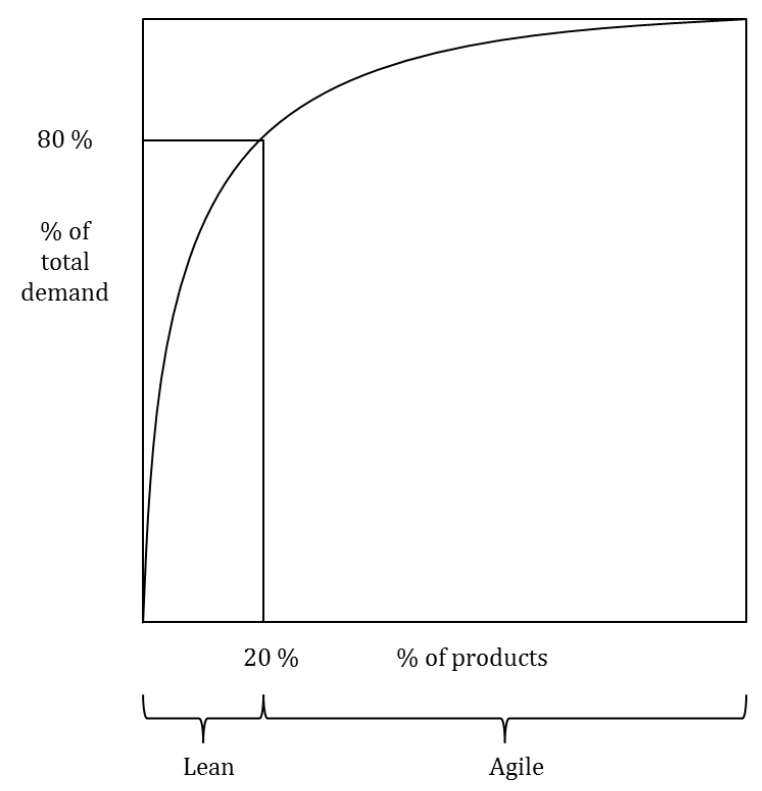

Figure 3. The pareto distribution (adapted from Christopher and Towill, 2001, pp. 240)

In healthcare separating the healthcare processes for routine patients from patients with more complicated healthcare needs, or acute patients and elective patients could be an implementation of this strategy. Using a fast track in emergency departments is an example of this approach, where patients with non-acute simple needs are managed separately (Considine et al., 2008; Ieraci, 2008; Sanchez et al., 2006; Vega and McGuire, 2007).

The last corner, the top right-hand one in Figure 2, uses the de-coupling strategy discussed earlier in this section (Towill and Christopher, 2002). Aronsson et al. (2011) though point out that being lean before the decoupling point and being agile after this point is not applicable in a healthcare setting, because the patient (customer) is involved in the whole process. Instead, choosing a strategy for every sub-processes, based on characteristics such as volume and variety is recommended. For example, a lean strategy becomes appropriate for standard blood analysis, where the variety is small and the volume large. This approach becomes similar to the discussion by Christopher (2000), where a lean approach is appropriate when variety is low and volume high and an agile approach is applicable when the opposite is faced.

To summarize the discussion on leagility, an elaboration on the time/space matrix adapted for the handling of a variable acute patient flow, is provided in Figure 4. It will be used to analyse parallels between groups of strategies used at the hospital with these three types of leagile approaches. To balance supply and demand of healthcare services Towill and Christopher (2005) also used the time/space matrix to distinguish four healthcare delivery pipelines. Although similarities are evident, this modified version is adapted for acute patient flows and is therefore not as general as the version by Towill and Christopher (2005). 


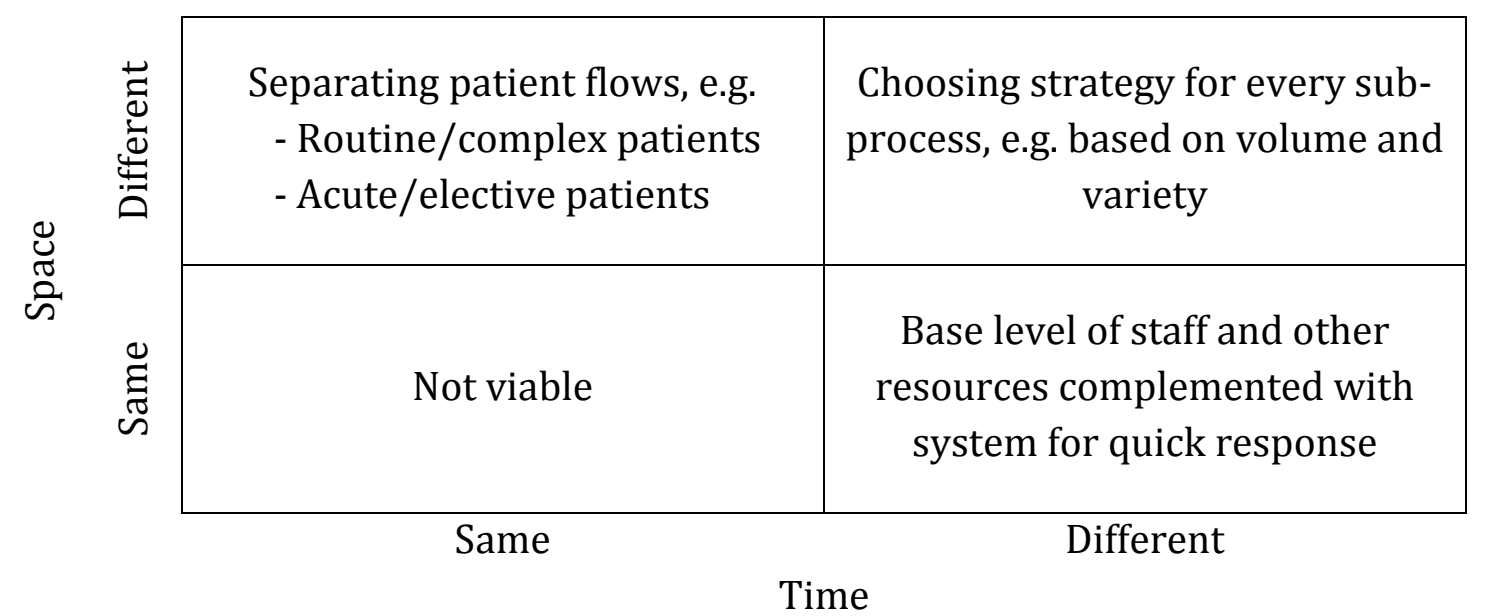

Figure 4 - Leagile approaches for managing variable acute patient flows

\section{Methodology}

The case hospital chosen is a university hospital in Sweden. Several of the clinical departments operating at the university hospital account for clinical results meeting the best international standards (Landstinget i Östergötland, 2014). In a comparison between the university hospitals in Sweden assessing medical quality, financial performance, customer satisfaction, waiting time and hygiene the university hospital also came out with a clear first place (Dagens Medicin, 2013-07-03). Consequently, the ability of the university hospital to manage a variable acute patient flow was anticipated to be of similar relative quality compared to other university hospitals. Therefore, the specific university hospital was of interest concerning the strategies used to manage a variable acute patient flow. Because the university hospital (hospital) studied includes multiple clinical departments, that have many characteristics of independent organisations, a single case study approach was chosen (Yin, 2009).

In line with recommendations from Eisenhardt (1989), constructs from literature on lean, agile and leagile were collected in order to produce an interview guide that captured these constructs. The interview guide, in its entirety, can be found in Appendix 1. Every question was not posed to every respondent; instead the interview guide was adapted for each interview. The following subjects were covered:

- Participating actors

- Overall strategic direction and aims in managing a variable acute patient flow

- Coordination, integration and collaboration between different actors and hierarchical levels as well as external collaborations

- Operational strategies related to scheduling, staffing, task and responsibility for different actors, patient distribution and transfers, acute versus elective patients, bed management, managing patient inflow and outflow. 
Each semi-structured interview was recorded, transcribed and sent to the respondent for confirmation. Due to theoretical saturation (Strauss, 1987), semi structured interviews with four department chiefs were used. The theoretical saturation was not due to these four describing the use of exactly the same strategies, but that the fourth interview resulted in few additional strategies.

Unstructured observations and interviews as well as observations on meetings were also used in order to gain an understanding of the context studied as well as actors within the system. This data triangulation (Patton, 2002) also gave a fuller picture of the organisation (Bonoma, 1985) and provided confirmation as well as disconfirmation of some opinions, beliefs and statements expressed by respondents in the interviews (Woodside, 2010). During the interviews, observations and meetings, formal strategy and planning documents were not specifically requested. Instead, specific documents have only been asked for if a respondent mentioned the document without being prompted. Due to the number of interviews performed with respondents from different parts of the organisation, the researchers are fairly confident that important strategy and planning documents have been identified. Formal documents that are not used in planning and decision-making have thus been disregarded. For a list on the information gathering activities, see appendix 2 .

By reporting partial results to a working team consisting of clinical department chiefs, empirical evidence could be verified. The final case description was also sent to three key informants (Yin, 2009), each of whom has in-depth knowledge of the hospital's operations; feedback was retrieved and incorporated in the description.

The analysis is divided into two parts, where the first one is a categorisation of the actions used to manage a variable acute patient flow in terms of leanness and agility. By going through all collected data, interviews, observation notes and documents all actions that could be interpreted as managing a variable acute patient flow were documented in a spreadsheet, 73 actions in total. The actions were then categorised into one of the six categories described in the frame of reference, except for those that did not match any category. A second researcher was used for investigator triangulation (Patton, 2002) and after discussions some actions were re-categorised or excluded, others put together or divided. All-in-all 50 actions remained.

The initial analysis and categorisation forms the basis for analysing the existence of leagile approaches, thus combinations of lean and agile actions. In Figure 4 three different leagile approaches for managing a variable acute patient flow are described. Each one of the 50 actions identified are categorised to one of these three leagile approaches. 


\section{Overview of the system}

Except for organ transplantation the hospital provides diagnostics, consultation and treatment within every medical speciality. The catchment area concerning highly specialised care includes one million residents. The hospital is also responsible for parts of the local health care service in the county. The hospital profiles itself through an advanced emergency and trauma care and a focus on highly specialised care and research. The six production units with operations at the teaching hospital are further divided into clinical departments. To provide an overview some general figures for the hospital are presented in Table 1.

\begin{tabular}{lll}
\hline Category & $\mathbf{2 0 1 1}$ & $\mathbf{2 0 1 2}$ \\
\hline Production & 570 beds & 572 beds \\
& 42,000 hospitalisation & 43,000 hospitalisation \\
& 15,000 operations & 17,000 operations \\
& 270,000 outpatient visits to & 285,000 outpatient visits to \\
& physician & physician \\
\hline Employees & 5,100 in total & 5,200 in total \\
& Nurses $35 \%$ & Nurses $35 \%$ \\
& Assistant nurses 22\% & Assistant nurses $22 \%$ \\
& Physicians $16 \%$ & Physicians $17 \%$ \\
& Management/administrative & Management/administrative \\
& 10\% & $10 \%$ \\
& Other $17 \%$ & Other $17 \%$ \\
\hline
\end{tabular}

Table 1 - The hospital in figures

A schematic picture of the patient flow at the hospital can be seen in Figure 5. It should be pointed out that the depicted patient flow represents patients admitted to a clinical department at the hospital.

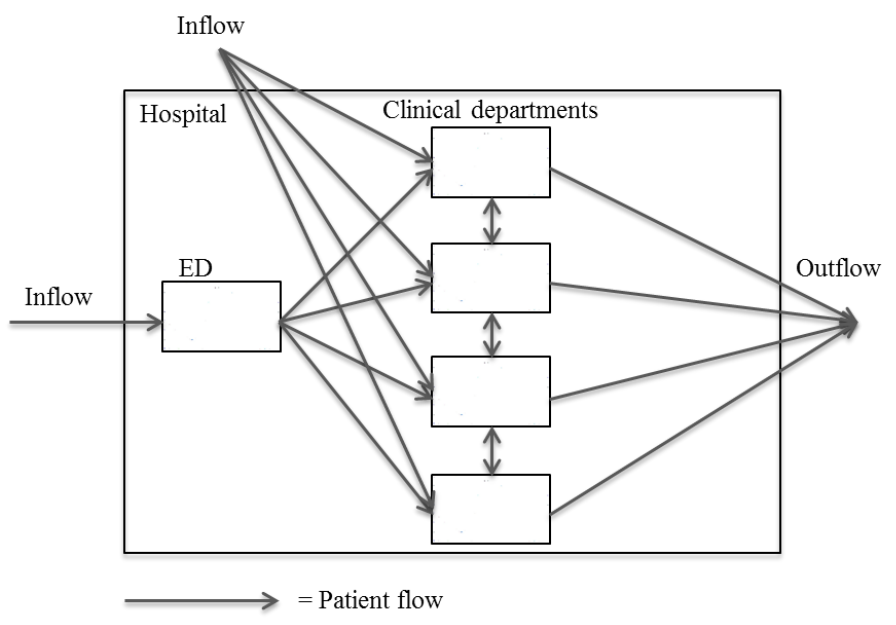

Figure 5 - An overview of the patient flow for patients admitted to an inpatient ward at the hospital 
Not all clinical departments are included in the study. Clinical departments belonging to the Internal medicine group (see Table 2) have, due to historical reasons, a joint responsibility to provide appropriate care for acute patients arriving at the emergency department with internal medicine issues. These departments thus have extended opportunities when choosing actions for managing a variable acute patient flow, and are therefore included in the study. When the clinical departments within the Internal medicine group are unable to admit internal medicine patients, most often the departments of Surgery or Neurology step in and admit these patients. Since this collaboration goes both ways, these two departments are also included in the study. A list of the included and not included clinical departments is provided in Table 2.

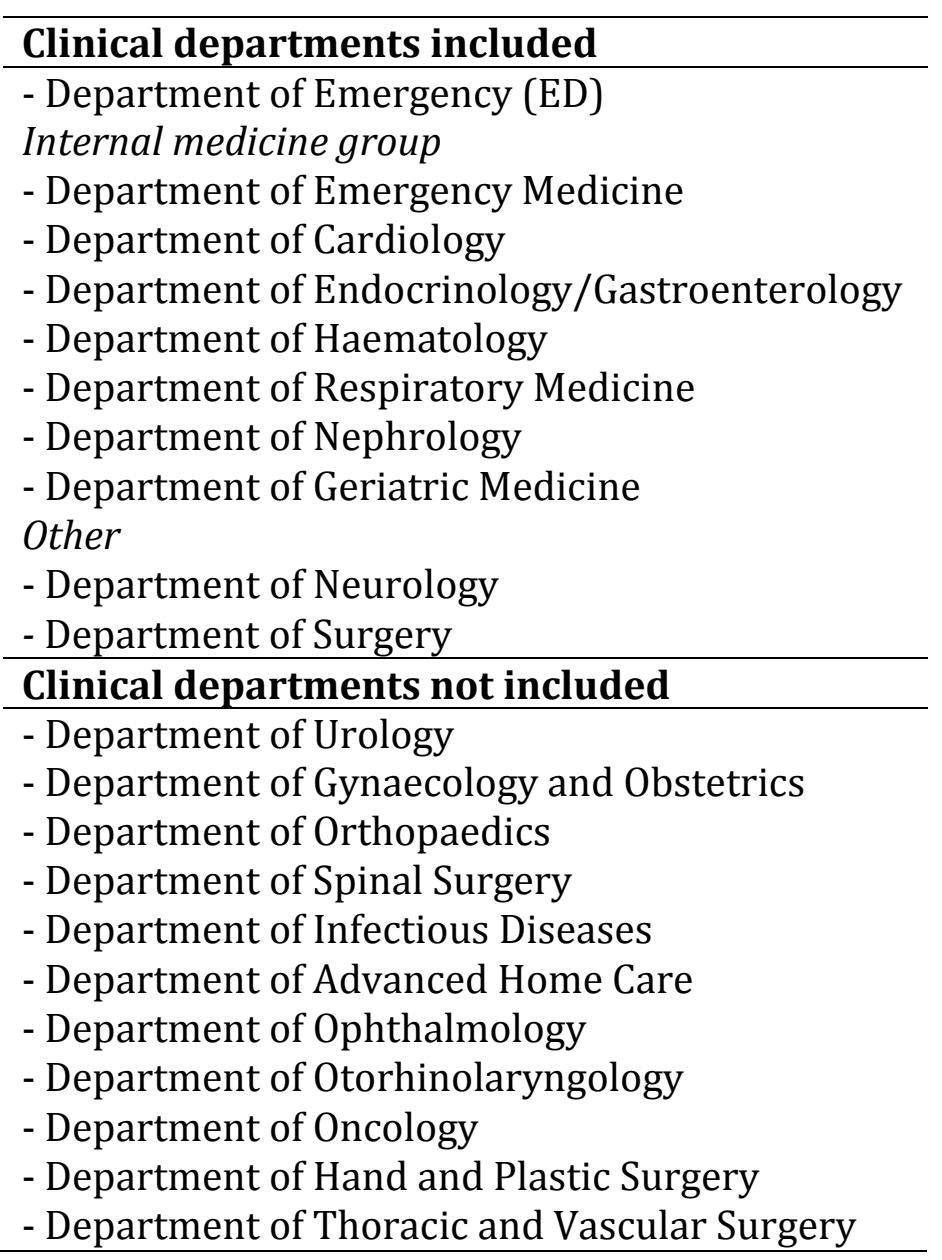

Table 2 - Clinical departments included and not included in the study

The emergency department at the hospital is a medical treatment facility specializing in acute care of patients who present at the hospital without prior appointment. The arrival pattern of patients visiting the emergency department is rather predictable concerning how it varies during the day and between days of the week. For clinical departments admitting patients from the ED, the variations are larger and more difficult to predict. For some clinical departments this can vary between 0 and 10 admissions per day. There is 
considerable variation on a weekly basis, but monthly and yearly variations on inflow from the ED are small.

Most clinical departments have acute and elective patient inflows, that do not originate from the ED. It is not unusual that patients need to be transferred between clinical departments during the care episode in the hospital. An internal investigation performed 2005-2006 concluded that approximately $40 \%$ of internal medicine patients were transferred between clinical departments at least once during their care episode. There are also variations on the length of stay and discharges for clinical departments.

The distribution of acute patients in need of admission from the ED is in first hand based on the medical needs of the patient. When the clinical department responsible for the appropriate treatment are not able to admit a patient other departments might need to admit that patient. This often has the effect of increased length of stay. Although the likelihood of early or late discharge is related to experience, risk taking and other individual characteristics of the physician, the importance of being admitted to the "right" clinical department is a more relevant factor for this study. The influence of individual characteristics of the physician on patient flow variability will therefore not be further explored. Altogether the patient flows at the hospital are subject to much variation. How this variation is managed is described below.

\section{Categorisation of strategies}

The categorisation of actions used to manage a variable acute patient flow is presented below. All of the actions below are used at the hospital. The six categories are provided, including the number of actions denoted within each category:

- Agile 1: Extending the use of a resource (7)

- Agile 2: Altering the amount of a resource, ahead of demand (9)

- Agile 3: Altering the amount of a resource, as a response to demand (12)

- Lean 1: An action that increases patient flow standardisation (7)

- Lean 2: An action that reduces the need for a resource (11)

- Lean 3: An action that directly manages external variation (4)

Since the appropriateness of actions used to manage a variable acute patient flow are not evaluated in this study the number of actions within each category are specified to give a hint on the usage of different types of strategies. A list of the 50 actions, as well as the categorisation can be seen in Appendix 3. The actions within each category are also described below.

\section{Agile 1: Extending the use of a resource}

There are seven actions (number 1-7 in Appendix 3) used to extend the use of a resource. Five of these are related to having extended tasks or assignments for personnel. To 
balance staffing between different wards at a clinical department, personnel can divide their efforts between wards, and some clinical departments have specific nurses or assistant nurses that only work where it is temporarily most needed (1). A central staffing function exists, from which additional personnel can be hired, but most bookings are longterm and short-term bookings are rarely possible (2).

When most clinical departments are fully occupied it can lead to extensive investigations at the ED, in hope of reaching decisions where patients do not need to be admitted (3). The relocation of patients between clinical departments is an action that can be used to free up a bed at a clinical department (4). Since the relocated patient is still under the medical responsibility of the clinical department, it requires that a physician takes the responsibility for the patient. When recurrent demand for relocation exists between two clinical departments a care agreement can be specified (5). This agreement specifies how the patients should be cared for to ensure a safe care process as well as routines and division of labour between the clinical departments.

Two actions are related to extending the use of rooms and beds by having flexible criteria for intake. By not explicitly deciding how many beds that are allocated for acute and elective patients at the clinical departments (6), the elective and acute patient ratio is allowed to vary, thus flexibility is created. Another similar action is to mix male and female patients in rooms with two beds or more (7). This action is only used as a last resort, and when medically justifiable.

\section{Agile 2: Altering the amount of a resource, ahead of demand}

Nine actions (number 8-16 in Appendix 3) relate to altering the amount of a resource ahead of demand, of which three are related to adapting staff levels to demand. At the ED staffing is adapted to the inflow of patients during day and night (8). At another clinical department physician staffing is increased during holidays due to higher patient inflow, in contrast to normal weekends when physician staffing is lower than weekdays (9). Some clinical departments use models where different work shifts are compensated differently (10), to make personnel less reluctant to work inconvenient hours and thereby enabling adjustment of work shifts to demand.

Three actions are concerned with adapting the availability of free beds to expected demand of acute patients. To relocate a patient occupying a bed with specific equipment, such as telemetric equipment, before there is an acute patient in need of the specific bed is one of these actions (11). This is most often executed as a preparation before the night, to simplify the admission process when many of the actors that work with admissions are not available. For beds with telemetry equipment, of which there are a limited number, this is a typical action and there are also other types of beds that are prioritised to have available. 
Based on the aim of even bed utilisation between clinical departments, a number of clinical departments can also dedicate beds to patients belonging to another clinical department (12). If there are insufficient beds, a choice can be made to decrease or stop the elective intake, in order to free up beds for expected acute patients. (13). This action can normally be executed to the forthcoming day and therefore has limited effect on the present situation and other actions are mostly chosen, e.g. utilising additional beds at different clinical departments.

Adapting discharges to patient inflow by discharging earlier in the day, and thereby liberating beds for arriving patients, is another sub-division where three actions have been acknowledged. One way of achieving this is to have the physician evaluate potential discharge patients early in the morning (14). Prior to this evaluation the nurses and/or assistant nurses have assembled information in the form of e.g. blood samples, EKG and observations to enable the decision on discharge. Another approach to enable early discharge is to use individualised rounds, meaning that patients who can potentially be discharged are assessed first (15). To decide upon early discharges the day before is another action to attain early discharges (16).

\section{Agile 3: Altering the amount of a resource, as a response to demand}

Altering the amount of a resource, as a response to demand is identified by twelve actions (number 17-28 in Appendix 3). Two of these are related to altering staff levels. Some clinical departments use models where separate work shifts are compensated differently. These models enable personnel to be sent home when there is nothing to do (17) and thus adapt staffing to demand. For clinical departments that do not have the situation where personnel can be sent home, e.g. due to unpredictable surges in acute patient inflow, these models often prove too costly. Due to sickness or patients with demanding care needs, additional nurses or assistant nurses can be called in (18), but extra personnel are seldom called in to open new beds.

Four actions are used to admit patients in excess of normal bed numbers. When this happens the amount of personnel and equipment per patient is decreased and thus the amount of these resources altered. The most common action of these four is to admit patients to additional beds (19). These beds are physical beds, sometimes located in regular patient rooms, but also often located in rooms intended for other activities, such as communal spaces or offices. The additional beds are often used by many clinical departments and are generally considered as unproblematic to use. The other three actions are however more problematic and less frequently used; to have patients in beds in excess of the additional ones (20), to place patients in beds in the corridor (21) or to have a patient spend the night at home or in a nearby hotel (22). These actions are used only as a last resort, and only when medically justifiable.

To open additional beds and supply additional personnel, and thus increasing the amount of these resources is used to counteract great strain on healthcare resources at the 
hospital in two ways. The first is to open an entire additional ward (23). This option is only used a few times a year, when the demand for beds exceeds the supply for a longer time than is normal. A clinical department can also be asked to temporarily open up a number of extra beds for acute patients (24).

Four actions are concerned with moving patients to set free beds at specific locations. When there is a lack of available beds at a hospital as a whole, collaboration between the three hospitals in the county is possible (25). For the clinical departments that have operations at several hospitals in the county, moving patients between these is also a possibility (26). To avoid bed blocking by an elderly patient who is medically ready for discharge, a bed can sometimes be provided at a short time care facility before admittance to a permanent care facility (27). Due to high pressure on personnel or beds, patients are sometimes discharged earlier than otherwise would be the case (28).

\section{Lean 1: An action that increases patient flow standardisation}

Seven actions (number 29-35 in Appendix 3) are used to standardise the patient flow for specific subsets of patients. The department of geriatric medicine has two beds allocated for patients that are expected to be discharged within 24 hours (29). To gather patients with short LOS and small deviations from expected LOS, the Department of Surgery and the Department of Urology have opened a joint ward (30) with the aim of a standardised and efficient care process.

When elective intake needs to be cancelled to avoid overcrowded outpatient wards a choice of which clinical departments should cancel elective intakes must be made. In general, the clinical departments that normally admit acute patients are often required to cancel elective intake (31). Clinical departments with only elective intake seldom have to cancel this intake, which leads to a standardisation of the patient flow at these clinical departments. For clinical departments with both elective and acute patients it is common to plan elective intake in order to have a fixed number of beds available for acute patients (32), and thereby aim for some standardisation in the patient flow.

The clinical departments within the internal medicine group have a joint responsibility to provide healthcare for general internal medicine patients. However, a special case is a memo between the department of emergency medicine and the department of cardiology stipulating the border between which patients should be admitted to each clinical department (33). The department of cardiology also has a routine together with ambulance personnel to bypass the ED for patients with specific heart issues (34). The ambulance personnel send an electrocardiogram to the clinical department and a nurse evaluates if the ambulance should go directly with the patient to the department of cardiology instead of the ED.

During periods when the local health service has reduced capacity to accept elderly patients who are medically ready for discharge, a temporary ward is introduced. This 
ward is staffed only with assistant nurses and is located at the department of geriatric medicine. If a clinical department has a patient who is medically ready for discharge and awaiting assistance from the local health service, a patient transfer to the temporary ward can free up a bed earlier (35).

\section{Lean 2: An action that reduces the need for a resource}

Eleven actions (number 36-46 in Appendix 3) have been identified with reducing the need for a resource. The timing of the discharge of a patient is important; five actions are thus used to avoid unnecessary hospital days and thereby reduce the need for resources. Some clinical departments adopt the action of discharging patients on weekends and not just on weekdays (36). To prepare for discharge in parallel with treatment is also used to enable discharge as soon as it is medically justified (37).

The local health services have specific assistance evaluators, working weekdays; this aids in discharge planning regarding after care, rehabilitation and admittances to care facilities. These assistance evaluators are located at the hospital, thus enabling faster and smoother discharge planning (38). To avoid prolonged LOS it also is desirable to begin discharge planning as early as possible after the patient is medically ready for discharge (39). As an exception, discharge planning can be called for before the patient is medically ready for discharge, e.g. when a patient needs medical equipment at home, or when some home alternations are needed before discharge (40).

To avoid unnecessary admissions and re-admissions and thus reduce the need for resources, six actions have been identified. At the department of neurology, some inpatient care is altered to outpatient care by sending patients home from the ED with a scheduled doctor's appointment instead of admission for inpatient care (41). For patients who are frequent visitors to the hospital and/or have complex healthcare needs, a project where they are assigned a personal care coach to simplify and structure all their contacts with healthcare, has been initiated (42). One of the aims of this action is to avoid unnecessary visits to the ED and subsequent admissions.

For elderly patients in poor health, a specific track on the ED is used (43). By having all appropriate competences available to quickly provide treatment and care for the patient, including established and fast communication with elderly care, many patient admissions can be avoided. This procedure is appropriate since elderly patients in poor health often have long LOS when admitted to inpatient care. Based on the same reasoning, advanced domiciliary services are provided by the local health services around-the-clock to enable chronically sick or elderly patients who need limited medical supervision provided by a physician or nurse, to stay at home (44).

By providing easily understood verbal and written information to patients with increased risk for readmission, the aim is to reduce the number of unnecessary readmissions (45). The county has also introduced an enhanced handoff process between inpatient care and 
primary care when discharging patients with increased risk of readmission (46). The physician at the inpatient ward is responsible for providing quick and standardised information concerning necessary actions to the physician in the primary care that receives medical responsibility for the patient after discharge from the hospital. The physician in the primary care should contact the patient within two workdays from the discharge date to ensure that the patient has understood their situation, and if necessary book a new appointment at the care centre.

\section{Lean 3: An action that directly manage external variation}

Of the four actions (number 47-50 in Appendix 3) that directly manage external variation, three are used to directly manage external variation by distributing acute patients. The hospital coordinators divide acute patients that need admission to an inpatient ward based on the aim that bed utilisation should not be too unevenly distributed between clinical departments (47), thus reducing variation in bed occupancy for the inpatient wards. Some inpatient wards also use a measure of how resource demanding the patients belonging to a care team are, and use this measure to allocate forthcoming admissions between the care teams (48). When a patient at the ED requires admission to a clinical department where a discharge is needed to free up a bed, the patient might have to wait at the ED for some time (49). The ED thereby reduces the variation in bed occupancy for the clinical department, with a risk of overcrowding of the ED's premises.

At the ED, the decision to admit or sending home a patient after diagnosis have been reached, are, to an uncertain extent, influenced by the availability of beds at inpatient wards in the hospital. When there is a lack of available beds, the physicians are more inclined to send patients home than admitting them to the hospital, this behaviour thus becomes one of the actions that directly manage external variation (50). 


\section{Combining strategies, leagile approaches?}

After discussing the categorisation of actions as lean or agile, the second part of the analysis discusses the use of leagile approaches, thus combinations of lean and agile actions when managing a variable acute patient flow. A leagile approach thus corresponds to a box in Figure 6. The content in the boxes correspond to examples of each leagile approach as well as a concluding comment on the degree of usage.

\begin{tabular}{|c|c|c|}
\hline 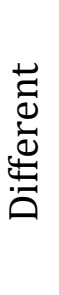 & $\begin{array}{l}\text { - Separating patient flows: } \\
\text { - enable efficient processes } \\
\text { - response to acute inflow } \\
\text { - Used mostly to coordinate } \\
\text { clinical departments }\end{array}$ & $\begin{array}{l}\text { - Some sub-processes specifically } \\
\text { managed, mostly related to: } \\
\text { - elderly patients } \\
\text { - patients with complex needs } \\
\text { - Limited usage identified }\end{array}$ \\
\hline \multirow[t]{2}{*}{$\underset{\tilde{\sigma}}{\stackrel{\Xi}{\sigma}}$} & Not viable & $\begin{array}{l}\text { - Base level of staff complemented } \\
\text { with possibility to alter levels } \\
\text { - Admitting patients in excess } \\
\text { - Used by clinical departments } \\
\text { independently }\end{array}$ \\
\hline & Same & \\
\hline
\end{tabular}

Figure 6 - Overview of the leagile approaches used to manage a variable acute patient flow

An example of a leagile approach can consist of many or few actions, while a single action can be a part of several examples of a leagile approach. Therefore, examples of leagile approaches are only discussed more broadly in this analysis and are not explicitly subdivided into the lean and agile components.

Several actions can be related to the leagile approach of having a base level of staff and other resources, complemented with a preparedness to respond to demand fluctuations (same space, different time in Figure 6). Managing staff levels is a major part of these actions, and some actions are concerned with adapting staff levels to demand, such as having models where different work shifts are compensated differently to enable adjustment of work shifts to demand. When these actions are not sufficient, personnel can be called in, staff balanced between wards or staff sent home. To increase the pressure on personnel, equipment and beds by admitting patients in excess of normal bed numbers is also used. Using additional beds and placing patients in beds in the corridor are examples of these actions. All of these actions are used by individual clinical departments, without intervention from other clinical departments, to manage their daily operations.

Separating patient flows is also a fundamental idea that can be distinguished in many of the actions used to manage a variable acute patient flow (different space, same time in Figure 6). A predominant part of the actions used to separate patient flows is used to be 
able to admit acute patients. Some examples of typical actions used for this purpose are: to open additional beds including additional personnel, moving patients to set free beds at specific locations or dedicating beds to patients belonging to other clinical departments. These actions are mainly used when a clinical department can't handle their patient inflow.

There are some actions used to separate patient flows to enable more efficient processes. When elective intake needs to be cancelled to avoid overcrowded inpatient wards, clinical departments that normally admit acute patients are more often required to cancel elective intake. Thus clinical department with only or predominantly elective patients are protected from variation and thereby given the possibility to adopt more lean processes. Clinical departments with elective patients who can be assessed as having more urgent medical needs are also more relieved from cancelling this intake. Other examples are beds allocated for patients with short LOS and small deviations from expected LOS, with the aim of a standardised and effective care process. To alter care from inpatient to outpatient status by sending patients home from the ED with a scheduled doctor's appointment instead of admission to an inpatient ward is another example.

A limited number of actions can be related to choosing a strategy for each sub-process (different space, different time in Figure 6). A majority of these have the objective of avoiding unnecessary admissions and re-admissions. Assigning a personal care coach to patients with complex healthcare needs is one action, another is to structure the handoff process between inpatient care and primary care when discharging patients with increased risk for readmission. For elderly patients in generally poor health, a specific track on the ED that quickly provides treatment and care as well as fast communication with elderly care is used to avoid unnecessary admissions. Advanced domiciliary services are also provided around-the-clock to enable chronically sick elderly patients who need limited medical supervision to stay at home.

A few actions are used to reduce the need for resources in specific parts of the patient flow. In periods of high demand an inpatient ward, staffed only with assistant nurses, is dedicated to patients that are medically ready for discharge and awaiting assistance from the local health service, thus enabling earlier discharge of patients from resource intensive wards. The department of cardiology also has a routine together with ambulance personnel to bypass the ED for patients with specific heart issues.

\section{Conclusions}

Actions from every lean and agile category derived from literature are used at the hospital. However, only four actions have been identified within the lean category directly manage external variation. Several actions within the third agile category, alter the amount of a resource as a response to demand, are used at the hospital. This can be deduced 
to insufficient level of the other two agile categories, since these are used more proactively.

There are difficulties categorising actions as lean or agile and some actions are easier and some are more difficult to categorise. E.g., the action to decide upon early discharges the day before (16), categorised to the agile category of altering the amount of a resource, ahead of demand could also be categorised to the lean category of actions that reduce the need for a resource. Here the crucial difference regards how the action is being used. When used due to a predicted surge in demand that needs to be addressed the action belongs to an agile category. However, when used on a regular basis a lean category seems more appropriate. The same reasoning can be used for the action of discharging patients on weekends and not just on weekdays (36), categorised as a lean action, since it is used on a regular basis. In conclusion, the distinctions are not always clear-cut.

From interviews it is clear that there is no hospital wide strategy for managing a variable acute patient flow. There is however an understanding that there is a need for better planning and control. The actions taken have therefore not been guided by an overall strategy. The actions have been implemented over time to solve local problems. The analysis is therefore that the problem to classify the actions into lean and agile categories to a large extent depends on the lack of an hospital wide strategy.

Aronsson et al. (2011) claim that lean inspired approaches in healthcare are often used to induce a change towards a process orientation by establishing proper planning and control of the patient flows, and denotes this "lean basic". Based on this reasoning many of the actions, mainly from lean categories, used at the hospital could be classified as lean basic. The fact that many of the actions are in the field of capacity planning suggests that this is an important aspect in the early stages of developing a lean or agile strategy. By arguing that a lean basic level is a prerequisite to fully attain the advantages of lean and agile process strategies it could be questioned if the benefits of lean and agile process strategies are reachable in the present situation.

Leagile approaches of all three combinations derived from literature are used at the hospital. These are however not as clear-cut as examples in literature and the division between the lean and agile parts of these leagile approaches are indistinct. An example is the actions used to separate patient flows mainly because a clinical department cannot handle their patient inflow, and not due to different patient groups being appropriate to manage through lean or agile process strategies. Hence, a categorisation of the lean and agile parts of the leagile approaches has not been presented in the paper. By exploring the use of leagile approaches in a university hospital with multiple and differentiated patient flows, this paper does fill a gap in literature identified by Rahimnia and Moghadasian (2010). Overall, the different leagile approaches discussed in this paper are in line with the healthcare delivery pipelines described by Towill and Christopher (2005). Hence, it cannot be concluded that there are any general difficulties or issues with mixing different 
leagile approaches. However an increased awareness and more active choices concerning which approaches should be used, and why, both at a departmental and hospital level are needed at the case hospital.

The study has been focused on actions and strategies used to handle a variable acute patient flow. In the frame of reference it is clear that both the lean and agile strategies have a wider scope, e.g. adaptation to new market opportunities and new technologies. These aspects are not covered in this paper.

\section{Future research}

Lean and agile strategies has been discussed extensively in literature. As far as the authors know this is one of the first case studies where actions used to handle a variable acute patient flow has been classified using the concepts of lean, agile and leagile.

In this study it has not been evaluated if the actions used to manage a variable acute patient flow are appropriate or not for the system. Intuitively, some actions are more appropriate than others based on different variables such as costs, time and strain on personnel. Further research concerning what types of strategies that are most appropriate, based on different variables, are therefore encouraged.

It would be difficult to evaluate the impact of lean, agile and leagile using this case, since the actions discussed have been implemented during different periods of time. To study certain actions among those reported in this study is interesting. One should though be aware that some actions might need supplementary actions to give the desired effect; which other actions that are needed is also of interest to increase the understanding of how healthcare systems, such as hospitals, behave.

The research reported in this paper is exploratory in its nature and there is a need for further studies within the field of research. The focus of the study has been on clinical departments that have both acute and elective patients. Based on theory a lean strategy is preferred when the production can be protected from fluctuations in demand (in industry accomplished by having inventory). One area for further studies would be regarding clinical departments with a high percentage of planned patients, e.g. eye surgery, or clinical departments with only acute patients.

\section{References}

Aitken, J., Christopher, M. and Towill, D. (2002), "Understanding, implementing and exploiting agility and leanness", International Journal of Logistics Research and Applications", Vol. 5, No. 1, pp. 59-74.

Allder, S., Walley, P. and Silvester, K. (2011), "Is follow-up capacity the current NHS bottleneck?", Clinical Medicine, Vol. 11, No 1, pp. 31-34. 
Arlbjörn, J. S. and Halldorsson, A. (2002), "Logistics knowledge creation: reflections on content, context and processes", International Journal of Physical Distribution \& Logistics Management, Vol. 32, No. 1, pp. 22-40.

Aronsson, H., Abrahamsson, M. and Spens, K. (2011), "Developing lean and agile health care supply chains", Supply Chain Management: An International Journal, Vol. 16, No. 3, pp. 176-183.

Bicheno, J., Anhede, P. and Hillberg, J. (2009), Lean Handbok för Service och Tjänster, Revere.

Bohmer, R.M.J. (2005), "Medicine's service challenge: blending custom and standard care", Health Care Management Review, Vol. 30, No. 4, pp. 322-330.

Bonoma, T.V. (1985), "Case research in marketing: Opportunities, problems, and a process", Journal of Marketing Research, Vol. 22, No. 2, pp.199-208.

Christopher, M. (2000), "The Agile Supply Chain - Competing in Volatile Markets", Industrial Marketing Management, Vol. 29, No. 1, pp. 37-44.

Christopher, M. and Towill, D.R. (2000), "Supply chain migration from lean and functional to agile and customised", Supply Chain Management: An International Journal, Vol. 5, No. 4, pp. 206-213.

Christopher, M. and Towill, D.R. (2001), "An integrated model for the design of agile supply chains", International Journal of Physical Distribution \& Logistics Management, Vol. 31, No. 4, pp. 235-246.

Considine, J., Kropman, M., Kelly, E. and Winter, C. (2008), "Effect of emergency department fast track on emergency department length of stay: a case-control study", Emergency Medicine Journal, Vol. 25, No. 12, pp. 815-819.

Dagens Medicin (2013-07-03), "Väntad seger för Linköping", http://www.dagensmedicin.se/nyheter/basta-sjukhuset-2012/vantad-seger-forlinkoping/ [Accessed July $3^{\text {rd } 2013] . ~}$

de Vries, J. and Huijsman, R. (2011), "Supply chain management in health services: an overview", Supply Chain Management: An International Journal, Vol. 16, No. 3, pp. 159-165.

Eisenhardt, K.M. (1989), "Building theories from case study research", Academy of Management Review, Vol. 14 No. 4, pp. 532-550.

Goldman, S. and Preiss, K. (1991), 21st Century Manufacturing Enterprise Strategy: An Industry Led View, Iacocca Institute, Bethlehem, PA.

Goldman, S.L., Nagel, R.N. and Preiss, K. (1995), Agile Competitors and Virtual Organizations: Strategies for Enriching the Customer, Van Nostrand Reinhold, New York, NY.

Grove A.L., Meredith J.O., Macintyre M., Angelis J., Neailey K. (2010a), “UK health visiting: challenges faced during lean implementation", Leadership in Health Services, Vol. 23, No. 3, pp. 204-218.

Grove A.L., Meredith J.O., Macintyre M., Angelis J., Neailey K. (2010b), "Lean implementation in primary care health visiting services in National Health Service UK", Quality and Safety in Health Care, Vol. 19, No. 5, pp. 1-5. 
Harrison, A., Christopher, M. and van Hoek, R. (1999), “Creating the agile supply chain”, Working paper, School of Management, Cranfield University, Cranfield.

Ismail, H. and Sharifi, H. (2006), "A balanced approach to building agile supply chains", International Journal of Physical Distribution and Logistics Management, Vol. 36, No. 6, pp. 431-444.

Ieraci, S., Digiusto, E., Sonntag, P., Dann, L. and Fox, D. (2008) "Streaming by case complexity: Evaluation of a model for emergency department Fast Track". Emergency Medicine Australasia, Vol. 20, No. 3, pp. 241-249.

Joosten, T., Bongers, I. and Janssen, R. (2009), “Application of lean thinking to health care: issues and observations", International Journal for Quality in Health Care Vol. 21, No. 5, pp. 341-347.

Kidd, P.T. (1995), "Agile Manufacturing: a strategy for the 21st century," Agile Manufacturing, IEE Colloquium on, pp. 1-6.

Landstinget i Östergötland (2014), Vård i världsklass, [Online], Avaliable: http://www.lio.se/Om-landstinget/Vard-i-varldsklass/ [Accessed Marsh 24th 2014].

Lillrank, P., Groop, J. and Venesmaa, J. (2011), "Processes, episodes and events in health service supply chains", Supply Chain Management: An International Journal, Vol. 16 No. 3, pp. 194-201.

Lin, C., Chiu, H. and Chu, P. (2006), “Agility index in the supply chain”, International Journal of Production Economics, Vol. 100, No. 2, pp. 285-299.

Mason-Jones, R., Naylor, B. and Towill, D. (2000), “Lean, agile or leagile? Matching your supply chain to the market place", International Journal of Production Research, Vol. 38, No. 17, pp. 4061-4070.

McKone-Sweet, K. E., Hamilton, P. and Wills, S. B. (2005), "The ailing healthcare supply chain: a prescription for change", Journal of Supply Chain Management, Vol. 41, No.1, pp. 4-17.

McLaughlin, C.P. (1996), "Why variation reduction is not everything: a new paradigm for service operations", International Journal of Service Industry Management, Vol. 7, No. 3, pp. 17-30.

Monden, Y. (1983), Toyota Production System: Practical Approach to Production Management, Industrial Engineering and Management Press, Atlanta.

Naylor, B., Naim, M. and Berry, D. (1999), "Leagility: Integrating the lean and agile manufacturing paradigms in the total supply chain", International journal of production economics, Vol. 62, No. 1-2, pp. 107-118.

Patton, M.Q. (2002), Qualitative Education and Research Methods, Sage Publication, Thousand Oaks, California, CA.

Qrunfleh, S. and Tarafdar, M. (2013) "Lean and agile supply chain strategies and supply chain responsiveness: the role of strategic supplier partnership and postponement", Supply Chain Management: An International Journal, Vol. 18, No. 6, pp. 571-582.

Radnor, Z., Walley, P., Stephens, A. and Bucci, G. (2006), "Evaluation of the lean approach to business management and its use in the public sector" (summary report). 
Research Findings No. 20/2006, Scottish Executive, Office of Chief Researcher, Edinburgh.

Rahimnia, F. and Moghadasian, M. (2010), "Supply chain leagility in professional services: how to apply decoupling point concept in healthcare delivery system", Supply Chain Management: An International Journal, Vol. 15, No. 1, pp. 80-91.

Ronen, B. and Pliskin, J. (2006), Focused operations management for health services organizations, Wiley, Hoboken.

Sanchez, M., Smally, A.J., Grant, R.J. and Jacobs, L.M. (2006) "Effects of a fast-track area on emergency department performance", The Journal of Emergency Medicine, Vol. 31, No. 1, pp. 117-120.

Shah, R., Goldstein, S.M., Unger, B.T. and Henry, T.D. (2008), "Explaining Anomalous High Performance in a Health Care Supply Chain*”, Decision Sciences, Vol. 39, No. 4, pp. 759-789.

Strauss, A.L. (1987), Qualitative analysis for social scientists, Cambridge University Press, Cambridge, England.

Towill, D.R. and Christopher, M. (2002), "The Supply Chain Strategy Conundrum: To be Lean Or Agile or To be Lean And Agile?", International Journal of Logistics: Research and Application, Vol. 5, No. 3, pp. 299-309.

Towill, D.R. and Christopher, M. (2005), "An evolutionary approach to the architecture of effective healthcare delivery systems", Journal of Health Organization and Management, Vol. 19, No. 2, pp. 130-147.

Vega V. and McGuire, S. (2007), "Speeding Up the Emergency Department: The RADIT Emergency Program at St. Joseph Hospital of Orange", HOSPITAL TOPICS: Research and Perspectives on Healthcare, Vol. 85 No. 4, pp. 17-24.

Walley, P., Silvester, K. and Steyn, R. (2006), "Managing Variation in Demand: Lessons from the UK National Health Service", Journal of Healthcare Management, Vol. 51, No. 5, pp. 309-320.

Womack, J.P., Jones, D.T. and Roos, D. (1990) The Machine that Changed the World, Rawson Associates, New York, NY.

Woodside, A.G. (2010), "Bridging the chasm between survey and case study research: Research methods for achieving generalization, accuracy and complexity", Industrial Marketing Management, Vol. 39, No.1, pp.64-75.

Yin, R. K. (2009), Case study research: Design and method (4th ed.), CA: Sage, Thousand Oaks. 


\section{Appendix 1 - Interview guide}

\section{Overall work to manage variation}

- Can you describe the overall strategies for managing a variable acute patient flow?

- In your position, what can you do to manage variation in the acute patient flow?

- Are there any limits to what you can do?

\section{Coordination}

- How is the work you do coordinated with the work of others to manage variation in the acute patient flow?

- Regarding a variable acute patient flow, do you cooperate with other positions/departments/wards within the hospital?

- Regarding a variable acute patient flow, do you cooperate with external parties outside the hospital (e.g. the patient inflow on the ED, or actions of the municipality)?

\section{Flexibility}

- Do you measure and follow up any kind of variation, for instance variation in length of stay, patient inflow or bed occupancy?

- How are peaks in bed occupancy and patient inflow, caused by the acute patient flow, managed?

- Do you have the possibility and/or time to prepare, and if so, how long in advance can you do that?

- Do you call-in staff?

- Move staff or change the personnel's work tasks?

- Cancel the elective intake?

$\circ$ Other actions?

- Those below gathered from the plan of action during bed shortage:

- Temporarily establishing additional beds

- Decreased elective intake

- Bed shortage meeting

- Cooperation within local health services (move patients to a corresponding unit at another hospital)

- Medically dischargeable patients (are temporarily moved to another unit in the hospital)

- Transferring a patient to another clinical department

- Standpoints to care at home

- Admitting patient to additional bed

- Opening an additional ward

- How is an acute patient flow, which is less than "normal", handled?

○ Do you send personnel home? 
- When there is a need of calling-in and/or sending home personnel, is there any difference in the actions when it comes to staff category?

- In your department, is any separation done between acute patients with different complexity in health issues?

\section{Scheduling}

- Which overall variables are taken into account in staff planning (e.g. occupancy, competence, or individual requests)

- Do you adjust the staffing after variations in the acute flow, for instance based on forecasts regarding acute patient inflow?

\section{Issues and possibilities}

- Which problems do you see in the current way of managing the acute patient flow?

- How would you like to improve it? 


\section{Appendix 2-Interviews and observations}

\begin{tabular}{|c|c|c|c|}
\hline Type & Position/organisational unit & Organisational unit/level & Duration (h) \\
\hline Observation, meeting & AIM group & Local Health Care Service (division) & 1 \\
\hline Unstructured interview & Department Chief & Department of Emergency & 2 \\
\hline Observation, meeting & Acute flow group & Hospital & 2 \\
\hline Unstructured interview/unstructured observation & Coordinator & Department of Cardiology & 4 \\
\hline Unstructured interview & Hospital coordinator & Department of Emergency & 0,5 \\
\hline Unstructured interview & Business developer & Department of Emergency & 0,5 \\
\hline Unstructured interview & Chief Medical Officer & Hospital & 2 \\
\hline Unstructured interview/unstructured observation & Coordinator & Department of Geriatric Medicine & 3 \\
\hline Unstructured interview/unstructured observation & Hospital coordinator & Department of Emergency & 3,5 \\
\hline Unstructured interview/unstructured observation & Doctor on duty & Department of Emergency Medicine & 4 \\
\hline Unstructured interview & Assistance evaluator & Municipality & 1 \\
\hline Observation, meeting & Acute flow group & Hospital & 2 \\
\hline Semi structured interview & Division Chief & Cardiology and Speciality Medicine Centre (division) & 1 \\
\hline Observation, meeting & Acute flow group & Hospital & 2 \\
\hline Semi structured interview & Healthcare Director & Hospital & 1,5 \\
\hline Semi structured interview & Chief Medical Officer & Hospital & 1,5 \\
\hline Semi structured interview & Division Chief & Local Health Care Service (division) & 1,5 \\
\hline Semi structured interview & Department Chief & Department of Surgery & 1,5 \\
\hline Semi structured interview & Department Chief & Department of Cardiology & 1,5 \\
\hline Observation, meeting & Hospital management group & Hospital & 2,5 \\
\hline Semi structured interview & Department Chief & Department of Neurology & 1 \\
\hline Semi structured interview & Department Chief & Department of Emergency Medicine & 1,5 \\
\hline Observation, meeting & Acute flow group & Hospital & 2 \\
\hline
\end{tabular}




\section{Appendix 3-Actions}

\begin{tabular}{|c|c|c|c|c|}
\hline Number & Action & Organisational usage & Category & Strategy \\
\hline 1 & Balance staffing between different wards and teams & Clinical department & Extending use & Agile \\
\hline 2 & Central staffing function, from which additional personnel can be hired & Hospital & Extending use & Agile \\
\hline 3 & Extended investigations at the ED & Clinical department & Extending use & Agile \\
\hline 4 & Relocate patients between clinical departments as a response to demand & Hospital & Extending use & Agile \\
\hline 5 & Care agreement between two clinical departments & Between clinical departments & Extending use & Agile \\
\hline 6 & Flexible number of beds allocated for acute and elective patients & Clinical department & Extending use & Agile \\
\hline 7 & Mixing male and female patients in rooms with two beds or more & Clinical department & Extending use & Agile \\
\hline 8 & Adapting staffing to the inflow of patients & Clinical department & Altering amount, ahead & Agile \\
\hline 9 & Physician staffing is increased during holidays & Clinical department & Altering amount, ahead & Agile \\
\hline 10 & Adapting staffing to demand by compensating work shifts differently & Clinical department & Altering amount, ahead & Agile \\
\hline 11 & Relocate patients between clinical departments in speculation & Hospital & Altering amount, ahead & Agile \\
\hline 12 & Dedicate beds for patients belonging to another speciality & Between clinical departments & Altering amount, ahead & Agile \\
\hline 13 & Decrease or stop elective intake to free up beds for expected acute patients & Hospital & Altering amount, ahead & Agile \\
\hline 14 & Evaluate patients that can potentially be discharged early in the morning & Clinical department & Altering amount, ahead & Agile \\
\hline 15 & Assess patients that potentially can be discharged first & Clinical department & Altering amount, ahead & Agile \\
\hline 16 & Decide upon early discharges the day before & Clinical department & Altering amount, ahead & Agile \\
\hline 17 & Sending personnel home when there is nothing to do & Clinical department & Altering amount, response & Agile \\
\hline 18 & Calling in additional nurses or assistant nurses & Clinical department & Altering amount, response & Agile \\
\hline 19 & Admit patients to additional beds & Clinical department & Altering amount, response & Agile \\
\hline 20 & Admit patients to beds in excess of regular and additional beds & Clinical department & Altering amount, response & Agile \\
\hline 21 & Place patients in beds in the corridor & Clinical department & Altering amount, response & Agile \\
\hline 22 & Have a patient spending the night at home or in a nearby hotel & Clinical department & Altering amount, response & Agile \\
\hline 23 & Open an additional ward & Hospital & Altering amount, response & Agile \\
\hline 24 & Temporarily open up a number of extra beds at a clinical department for acute patients & Hospital & Altering amount, response & Agile \\
\hline 25 & Moving patients between hospitals & Between hospitals & Altering amount, response & Agile \\
\hline 26 & Moving patients between wards at different hospitals & Clinical department & Altering amount, response & Agile \\
\hline
\end{tabular}




\begin{tabular}{|c|c|c|c|c|}
\hline Number & Action & Organisational usage & Category & Strategy \\
\hline 27 & Provide a place at a short time care facility before admittance to a permanent care facility & $\begin{array}{l}\text { Between hospital and local } \\
\text { health services }\end{array}$ & Altering amount, response & Agile \\
\hline 28 & Discharge a patient earlier than otherwise would be the case & Clinical department & Altering amount, response & Agile \\
\hline 29 & Beds allocated for patients that are expected to be discharged within 24 hours & Clinical department & Patient flow standardisation & Lean \\
\hline 30 & Joint ward for patients with short LOS and small deviations from expected LOS & Between clinical departments & Patient flow standardisation & Lean \\
\hline 31 & $\begin{array}{l}\text { Clinical departments with predominantly elective intake are rarely required to cancel elective intake } \\
\text { to accept acute patients }\end{array}$ & Hospital & Patient flow standardisation & Lean \\
\hline 32 & Schedule elective intake to have a fixed number of beds available for acute patients & Clinical department & Patient flow standardisation & Lean \\
\hline 33 & Stipulated boarder between which patients should be admitted to which clinical department & Between clinical departments & Patient flow standardisation & Lean \\
\hline 34 & Bypass the ED for patients with specific heart issues & Between clinical departments & Patient flow standardisation & Lean \\
\hline 35 & $\begin{array}{l}\text { Ward for patients that are medically ready for discharge but awaits assistance from local health } \\
\text { services }\end{array}$ & Hospital & Patient flow standardisation & Lean \\
\hline 36 & Discharge patients on weekends and not just on weekdays & Clinical department & Reduced need for a resource & Lean \\
\hline 37 & Prepare for discharge in parallel with treatment & Clinical department & Reduced need for a resource & Lean \\
\hline 38 & $\begin{array}{l}\text { Assistance evaluators located at the hospital, which enables a faster and smoother discharge } \\
\text { planning }\end{array}$ & $\begin{array}{l}\text { Between hospital and local } \\
\text { health services }\end{array}$ & Reduced need for a resource & Lean \\
\hline 39 & Summon for discharge planning as early as possible after the patient is medically ready for discharge & Clinical department & Reduced need for a resource & Lean \\
\hline 40 & Discharge planning called for before the patient is medically ready for discharge & Clinical department & Reduced need for a resource & Lean \\
\hline 41 & $\begin{array}{l}\text { Changing inpatient care to outpatient care by sending patients home from the ED with a scheduled } \\
\text { doctors appointment }\end{array}$ & Clinical department & Reduced need for a resource & Lean \\
\hline 42 & $\begin{array}{l}\text { Personal care coach assigned for patients that are frequent visitors to the hospital and/or have } \\
\text { complex healthcare needs }\end{array}$ & Hospital & Reduced need for a resource & Lean \\
\hline 43 & $\begin{array}{l}\text { Specific track on the ED for elderly where all appropriate competences to quickly provide treatment } \\
\text { and care are available }\end{array}$ & Clinical department & Reduced need for a resource & Lean \\
\hline 44 & $\begin{array}{l}\text { Advanced domiciliary services provided around-the-clock for elderly in need of limited medical } \\
\text { supervision }\end{array}$ & Clinical department & Reduced need for a resource & Lean \\
\hline 45 & $\begin{array}{l}\text { Provide easily understood verbal and written information to patients with increased risk for } \\
\text { readmission }\end{array}$ & Hospital & Reduced need for a resource & Lean \\
\hline 46 & $\begin{array}{l}\text { Enhanced handoff process between inpatient care and primary care when discharging patients with } \\
\text { increased risk for readmission }\end{array}$ & $\begin{array}{l}\text { Between hospital and local } \\
\text { health services }\end{array}$ & Reduced need for a resource & Lean \\
\hline 47 & Divide acute patients that need admission evenly between clinical departments & Hospital & Manage external variation & Lean \\
\hline 48 & $\begin{array}{l}\text { Allocate admissions between care teams based on measuring how resource demanding the patients } \\
\text { belonging to the care teams are }\end{array}$ & Clinical department & Manage external variation & Lean \\
\hline 49 & $\begin{array}{l}\text { Requiring patients to wait at the ED for some time before admission to a clinical department where a } \\
\text { discharge is needed to free up a bed }\end{array}$ & Between clinical departments & Manage external variation & Lean \\
\hline 50 & $\begin{array}{l}\text { The availability of beds at inpatient wards sometimes influence the decision to admit or sending } \\
\text { home a patient from the ED }\end{array}$ & Clinical department & Manage external variation & Lean \\
\hline
\end{tabular}

